\title{
More than meets the eye: deafness and in/visible disabilities
}

\author{
Cite as: CMAJ 2017 April 3;189:E506-7. doi: 10.1503/cmaj.160905
}

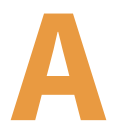

t the conclusion of World War I, Arthur Holmes, Supervisor for the Blind and the Deaf at the United States Veterans' Bureau, wrote, "Blindness ... is in almost every case a self-evident disability which appeals strongly to the sympathies of the general public." ${ }^{1} \mathrm{He}$ contrasted the treatment of veterans who had been blinded during combat, with their readily apparent eye bandages or use of canes, with that of their counterparts who were deafened, whom the public - often unaware of their hearing loss - regarded with less empathy. ${ }^{1}$

Holmes' term "self-evident disability" functions synonymously with what we call an invisible or hidden disability today: disabilities not immediately apparent to observers. This consideration of public perception is built into the Americans with Disabilities Act of 1990, which classifies as disabled any individual who has a substantially limiting impairment, has a record of such impairment or "is regarded as having such an impairment." 2

The concept of the self-evident and, in contrast, the hidden disability assumes a binary understanding of disability as either visible or invisible. However, deafness shows this dichotomy to be precarious. Early 20th-century military and medical authorities determined when deafness should be made visible. Specifically, physicians aimed to make deafness visible for diagnosis and invisible after treatment or therapy. In the immediate aftermath of World War I, in which thousands of servicemen were temporarily or permanently deafened, two features of the treatment of deafness show how the condition was made both visible and invisible: the audiograms that visually charted hearing status, and the lip-reading therapy used to evade detection of hearing loss.

\section{Audiograms}

An audiogram is a graphical depiction of one's hearing acuity that renders deafness visible and thereby allows it to be diagnosed and compared. However, before audiograms could illustrate useful information for hearing specialists, a device to accurately measure sound - the audiometer - was necessary. The Western Electric 1-A that physicists Harvey Fletcher and Robert Wegel patented in 1914 emerged as the first commercially available audiometer in the US. Using information from the audiometer, data points could be charted to form an audiogram. The $x$-axis depicts soundwave frequency, with pitch increasing from left to right. The y-axis shows intensity or volume. An individual's hearing threshold is the softest volume heard at various frequencies. Sounds softer than one's threshold curve - or above these points - cannot be heard; therefore, the further down the chart the points are plotted, the worse the hearing.

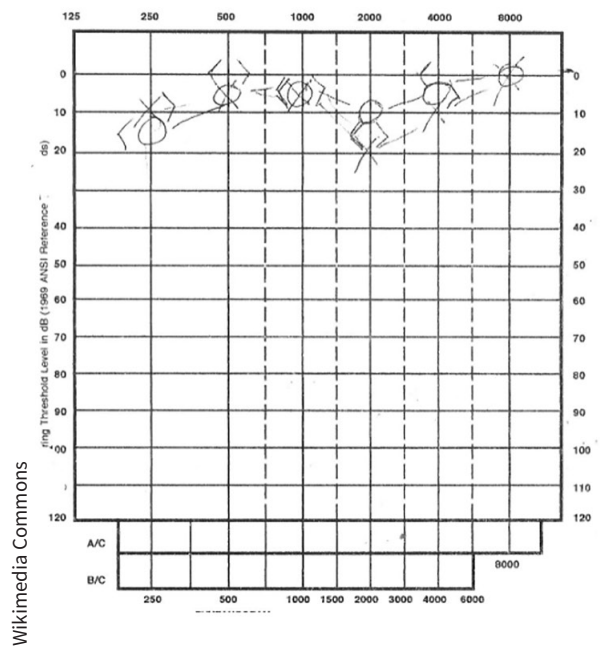

Audiograms established a certain depiction of deafness and hearing loss. Soon after the introduction of audiograms, medical journals began including them as illustrations in hearing-related articles, and physicians included them in their clinical reports to serve as ideal types for others to study and compare. Thus, these graphical depictions of hearing sensitivity enabled physicians to "calibrate their eyes." 3

Otolaryngologists Harold M. Hays and William Nemzek published a clinical report on hearing loss in The Laryngoscope in 1926 that featured 11 audiograms. ${ }^{4}$ These different "graphic pictures," as they referred to them, represented various "pathological conditions of the ear." 4 As Hays and Nemzek argued, audiograms allowed physicians to see and diagnose differences in causes of hearing loss quickly. As they reported in their article, Chart 1 represented a case of hearing loss due to impacted earwax; Chart 6 , in com-

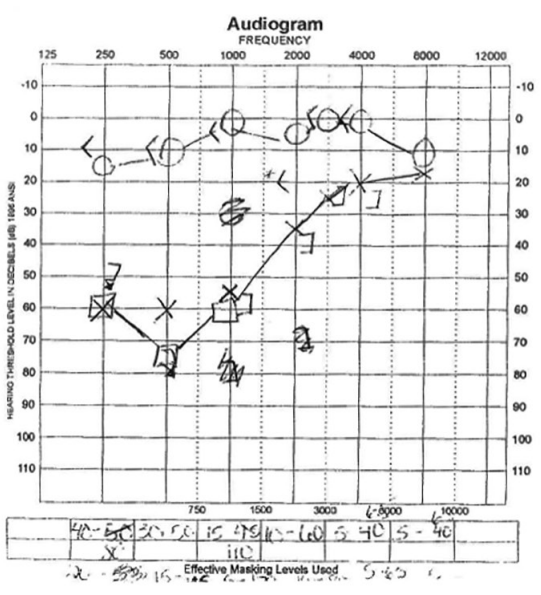

Audiograms showing normal hearing (left) and hearing loss associated with Ménière disease (right) (published under Creative Commons Attribution-ShareALike Licence; available at https://commons.wikimedia. org/wiki/File: Menieres-hearing-los.png). 
parison, showed a patient with chronic progressive hearing loss over three years; and Chart 8 was the audiogram of a "deaf mute," an individual who was born or became deaf before acquiring spoken language. ${ }^{4}$

Although these charts helped physicians recognize various degrees of hearing loss, a larger collection of audiograms across the hearing spectrum helped them visually distinguish good from bad hearing and expand diagnoses of different causes of hearing loss. The US Public Health Service commissioned Willis C. Beasley, a biophysicist from the Division of Public Health Methods at the National Institutes of Health, to assess the state of the nation's hearing in 1935 and 1936 by household censuses in 83 cities. Nine thousand people were examined and measured audiometrically. With these results plotted on audiograms, physicians could differentiate visually normal from abnormal hearing. With audiograms that wrote sound, physicians could diagnose hearing loss and prescribe instruction in lip-reading to help veterans who were deaf to read silence.

\section{Lip-reading}

Training for lip-reading long preceded World War I. By the late 19th century, lipreading and speech training reigned supreme in the civilian instruction of children who were deaf. War did, however, medicalize and militarize lip-reading instruction. An aural rehabilitation centre was opened in 1918 by order of the Surgeon General at General Hospital no. 11 in Cape May, New Jersey, where just over 100 soldiers received training in lip-reading. Courses averaged 2.7 months and aimed to help veterans who were deaf to communicate but also to keep their disability hidden. The ultimate goal was for these men to pass for hearing people. Although many struggled $-6 \%$ were reported to have understood less than $60 \%$ of speech - over half were considered to have excelled. ${ }^{5}$ As one more experienced serviceman told a new arrival:

A fellow don't need to hear ... I have not took many lessons but I can read the lips a little now. I see a fellow here the other day. You wouldn't know he was totally deef [sic]. He could read the lips so good. He was home on a furlough and his parents didn't know he was deef. ${ }^{5}$

Other success stories tell of girlfriends and family members who did not initially believe that their loved ones, who were skillfully conversant, could not hear. Imperceptible deafness was the objective of lip-reading instruction.

In a report published in The Laryngoscope in 1922, Dr. Gordon Berry praised the work of the Army Lip-Reading School. He admitted that "Lip-reading is far from a perfect substitute for hearing," but, he explained, "it is the best we have."

What was the alternative to lip-reading and speech training? Use of American Sign Language. However, physicians did not recommend this course. First, signing required not only learning a new language but also gaining acceptance into the culture of the community of deaf people. This cultural approach to deafness was outside the medical domain and therefore beyond the realm of medical knowledge and authority. Further, physicians saw sign language as a visible marker of disability and, accordingly, a visible sign of medical failure of otological treatment and lipreading therapy. To abandon lip-reading training for sign language, thus, was to admit medical defeat.

Hays and Nemzek opined in their article about a young patient who was deaf but had some level of residual hearing that cultivating whatever potential hearing remained was worth the intense effort required. "It would be sad," they argued, "to consign such a child to the sign language group." 4

And yet, without any visible indication of disability, because wearable hearing aids were not widely sold until the late 1930s, veterans who were deafened during war were often socially disabled. According to Holmes, ${ }^{1}$ soldiers who were deaf elicited less sympathy. Because their deafness was not self-evident and their conversational skills were affected, the public often considered them "dull and unsocial."

Holmes was not alone in this assessment. Dr. Charles Richardson, an otolaryngologist in the Medical Corps, acknowledged,

We are all well aware that most normal hearing persons have an aversion towards conversing with the hard of hearing or deaf ... [while] the blind has a serene mind born of the knowledge that all mankind extends to him a helping hand. ${ }^{6}$

Hiding one's disability by reading lips, then, also required personal fortitude.

With wartime advances in audiometry and lip-reading instruction, hearing specialists and veterans who were deaf learned to calibrate their eyes - the first group to interpret written sound, and the latter to read silent speech. As a result, deafness was rendered both visible and invisible.

\section{Katherrine Healey MA MPhil}

Program in the History of Science and Medicine, Yale University; and McDougal Graduate Teaching Fellow, Yale Center for Teaching and Learning, New Haven, Conn.

\section{References}

1. Holmes AE. The difference between the men who were blinded and who were deafened in the World War. Am Ann Deaf 1923;68:248-50.

2. Americans With Disabilities Act of 1990, Pub. L. No. 101-336, 104 Stat. 328 (July 26, 1990).

3. Daston L, Galison P. Objectivity. New York: Zone Books; 2007.

4. Hays H, Nemzek W. Clinical observations of the use of the audiometer in testing the hearing. Laryngoscope 1926;36:565-72.

5. Berry G. Is adult lip-reading worthwhile? A detailed study of 108 cases. Laryngoscope 1922; 32:654.

6. Richardson CW. Reconstruction of defects of hearing and speech. Ann Am Acad Pol Soc Sci 1918;80:35-9.

This article has been peer reviewed. 